\title{
Erratum to: A wedge-based approach to estimating health co-benefits of climate change mitigation activities in the United States
}

\author{
John M. Balbus • Jeffery B. Greenblatt • Ramya Chari • \\ Dev Millstein • Kristie L. Ebi
}

Published online: 6 February 2015

(C) Springer Science+Business Media Dordrecht 2015

\section{Erratum to: Climatic Change, Volume 127, Issue 2, pp 199-210 DOI 10.1007/s10584-014-1262-5}

Immediately after online publication of our article, the authors recognized that an error had been made in the calculation of the health co-benefits associated with the "wedge" obtained from greater efficiency for direct fuel end-use in buildings. The error changes the upper bound reported for potential benefits from $\$ 30$ Billion to $\$ 14$ Billion under our baseline scenario and from \$56 Billion to \$24 Billion under our optimistic rapid implementation scenario. The estimates of benefits from the remaining wedges are unchanged, and conclusions of this paper that potential co-benefits are substantial and that it is informative to compare the health benefits of equal amounts of carbon dioxide emissions reduction from different strategies remain the same.

This wedge differed from the other wedges in being an "area source" rather than associated with air pollution from electric generating units or mobile sources. To provide a corrected estimate we used an alternative estimation method for health co-benefits associated with one wedge of $\mathrm{CO}_{2}$ reductions from direct fuel end-use in buildings, based on data from the National Emissions Inventory for direct fuel combustion in residential and commercial/ institutional buildings, and using the economic benefits per ton calculated for area sources by (Fann et al. 2012). This method resulted in an estimate of $\$ 3.6$ billion of health benefits

The online version of the original article can be found at http://dx.doi.org/10.1007/s10584-014-1262-5.

J. M. Balbus $(\bowtie)$

National Institute of Environmental Health Sciences, 31 Center Drive, Room B1C02, Bethesda, MD

20892-2256, USA

e-mail: john.balbus@nih.gov

J. B. Greenblatt • D. Millstein

Lawrence Berkeley National Laboratory, Berkeley, CA, USA

R. Chari

RAND Corporation, Santa Monica, CA, USA

K. L. Ebi

University of Washington, Seattle, WA, USA 
with the baseline scenario and $\$ 6.8$ billion with the optimistic scenario in 2020 , without adjusting population (from 2005) or emissions (from 2008) to 2020. Because of the differences in methods, these figures are not directly comparable to the figures for the other wedges in the manuscript. Nonetheless, they demonstrate potential benefits in the same order of magnitude as the other wedges. The authors regret this error but stand by the methods and assumptions used in generating estimates of health co-benefits for the remaining nine wedges.

\section{REVISED ABSTRACT}

While it has been recognized that actions reducing greenhouse gas (GHG) emissions can have significant positive and negative impacts on human health through reductions in ambient fine particulate matter $\left(\mathrm{PM}_{2.5}\right)$ concentrations, these impacts are rarely taken into account when analyzing specific policies. This study presents a new framework for estimating the change in health outcomes resulting from implementation of specific carbon dioxide $\left(\mathrm{CO}_{2}\right)$ reduction activities, allowing comparison of different sectors and options for climate mitigation activities. Our estimates suggest that in the year 2020, the reductions in adverse health outcomes from lessened exposure to $\mathrm{PM}_{2.5}$ would yield economic benefits in the range of $\$ 6$ to $\$ 14$ billion (in 2008 USD), depending on the specific activity. This equates to between $\$ 40$ and $\$ 93$ per metric ton of $\mathrm{CO}_{2}$ in health benefits. Specific climate interventions will vary in the health co-benefits they provide as well as in potential harms that may result from their implementation. Rigorous assessment of these health impacts is essential for guiding policy decisions as efforts to reduce GHG emissions increase in scope and intensity.

\section{Reference}

Fann N, Baker KR, Fulcher CM (2012) Characterizing the $\mathrm{PM}_{2.5}$-related health benefits of emission reductions for 17 industrial, area and mobile emission sectors across the U.S. Environ Int 49:141-51 